\title{
BMJ
}

\section{Effect of reducing caffeine intake on birth weight and length of gestation: randomised controlled trial}

\author{
Bodil Hammer Bech, assistant professor, ${ }^{1}$ Carsten Obel, assistant professor, ${ }^{1}$ Tine Brink \\ Henriksen, consultant, ${ }^{2}$ Jørn Olsen, professor ${ }^{3}$
}

${ }^{1}$ Institute of Public Health, Department of Epidemiology, University of Aarhus, 8000 Aarhus, Denmark

${ }^{2}$ Perinatal Epidemiology Research Unit, Aarhus University Hospital, Skejby, Denmark

${ }^{3}$ Department of Epidemiology, University of California, LoS Angeles, USA

Correspondence to:

B HBech bhb@soci.au.dk

doi: 10.1136/bmj.39062.520648.BE

\section{ABSTRACT}

Objective To estimate the effect of reducing caffeine intake during pregnancy on birth weight and length of gestation.

Design Randomised double blind controlled trial. Setting Denmark.

Participants 1207 pregnant women drinking at least three cups of coffee a day, recruited before 20 weeks' gestation. Interventions Caffeinated instant coffee (568 women) or decaffeinated instant coffee (629 women).

Main outcome measures Birth weight and length of gestation.

Results Data on birth weight were obtained for 1150 liveborn singletons and on length of gestation for 1153 liveborn singletons. No significant differences were found for mean birth weight or mean length of gestation between women in the decaffeinated coffee group (whose mean caffeine intake was $182 \mathrm{mg}$ lower than that of the other group) and women in the caffeinated coffee group. After adjustment for length of gestation, parity, prepregnancy body mass index, and smoking at entry to the study the mean birth weight of babies born to women in the decaffeinated group was $16 \mathrm{~g}$ (95\% confidence interval -40 to 73 ) higher than those born to women in the caffeinated group. The adjusted difference (decaffeinated group-caffeinated group) of length of gestation was -1.31 days ( -2.87 to 0.25$)$.

Conclusion A moderate reduction in caffeine intake in the second half of pregnancy has no effect on birth weight or length of gestation.

Trial registration Clinical Trials NCT00131690.

\section{INTRODUCTION}

Exposure to caffeine in adults is mainly through the consumption of coffee. ${ }^{1}$ The half life of caffeine is 2.5 to 4.5 hours in non-pregnant women but longer during pregnancy, especially in late pregnancy. Caffeine is rapidly absorbed from the digestive system and passes freely across the placenta. ${ }^{2}$ In addition, fetuses do not metabolise caffeine well. ${ }^{3}$ Caffeine increases the levels of circulating catecholamines, ${ }^{4}$ which may cause uteroplacental vasoconstriction and fetal hypoxia, all of which possibly reduce fetal growth. Caffeine also increases cellular cyclic adenosine monophosphate, which may influence cell development. ${ }^{5}$
Pregnant women with a high caffeine intake (>300 mg a day) have been shown to give birth to babies with a birth weight 100-200 $\mathrm{g}$ lower than those of women with a low caffeine intake ${ }^{6-8}$ although not all studies found this association. ${ }^{910}$ A high daily caffeine intake has also been associated with an increased risk of giving birth to small for gestational age or low birth weight $(<2500 \mathrm{~g})$ babies, ${ }^{6}{ }^{11-14}$ but not all studies found this association. ${ }^{15-18}$ Most studies found no association between caffeine intake and preterm birth. ${ }^{19}$ Some have shown an association between caffeine intake during pregnancy and miscarriage, ${ }^{2021}$ but not all. ${ }^{2223}$ These conflicting results have puzzled public health authorities, and in some countries pregnant women are warned against caffeine consumption.

Women with a high caffeine intake during pregnancy differ in many ways from women with a low or no caffeine intake. They smoke more, have a higher alcohol intake, and have attained a lower level of education. ${ }^{12}{ }^{18}$ Despite attempts to control for these factors there are limits as to how much can be controlled in non-experimental studies.

We carried out a randomised double blind trial to estimate the effect of reducing caffeine intake on birth weight and length of gestation.

\section{METHODS}

We recruited Danish speaking pregnant women who consumed at least three cups of coffee a day and who were less than 20 weeks pregnant. Eligibility criteria included no history of a low birthweight baby $(<2500 \mathrm{~g})$, preterm delivery, kidney diseases, epilepsy, diabetes, or metabolic disorders.

From April 1996 to April 1998 we sent a questionnaire to all pregnant women booking for delivery at the Department of Obstetrics, Aarhus University Hospital, to assess coffee intake. At around 16 weeks of pregnancy we contacted those who had stated a daily intake of at least three cups of coffee. Eligible women who agreed to participate received detailed information on the study and a consent form.

From April 1998 to January 2002 we recruited eligible participants through the Danish national birth cohort. ${ }^{24}$ Participants in the cohort completed a telephone interview around 12 weeks of pregnancy that included information on the inclusion criteria. Eligible 
women were again informed about the study and recruited if they had signed the consent form.

\section{Randomisation and follow up}

The women were randomised to receive caffeinated instant coffee or decaffeinated instant coffee. We bought the coffee from the manufacturer, in identical boxes without labels. The women were allocated to either group by a computer generated randomisation schedule and assigned serial numbers in balanced blocks of six. Staff not in contact with participants and endpoint data applied a label with the serial number to each of the boxes according to the randomisation schedule. After the project coordinator (BHB) had received the consent form (at about 18 weeks' gestation) she posted six boxes of coffee to each participant, who were registered with the serial number applied to the box. BHB and the participants were blinded to the type of coffee, and the blinding was broken only at the end of the data analyses. The women could request as much coffee as they needed free of charge.

We asked the women to replace their usual coffee with that provided, but we did not advise them on how much to drink or ask them to avoid regular coffee offered by others or intake of other caffeinated beverages such as tea, cocoa, or cola. The women were interviewed throughout pregnancy to obtain data on daily consumption of the study coffee, other caffeinated beverages (coffee, tea, cola, or cocoa), and smoking status. The interviews were scheduled at gestational weeks 20, 25, and 34 and at four weeks after the expected date of delivery. In the final interview we asked the women to guess (or state "don't know") which type of coffee they had received.

\section{Outcome measures}

The main outcomes were birth weight and length of gestation, which we obtained, along with date of birth, from the Danish national birth register using the mother's personal identification number. If data were missing $(n=29)$ we used information from the telephone interview four weeks after the expected date of delivery. Gestational age at delivery was estimated by ultrasonography for $94 \%$ of the participants and by the date of the last menstrual period for the remaining women. From the national birth register we obtained information on length, head circumference, abdominal circumference, placental weight, and Apgar score to use for secondary analyses.

\section{Statistical analysis}

We analysed data on an intention to treat basis, blinded to coffee exposure. We compared both groups at baseline for maternal age, parity, education, smoking status, and prepregnancy weight and height. For crude analyses we used Student's $t$ test to compare mean birth weight in the two groups and Wilcoxon's rank sum test to compare mean gestational age. To produce more valid estimates we adjusted for several potential confounders selected a priori and recorded at baseline; gestational age (in the analysis of birth weight) and prepregnancy body mass index, parity, and smoking status, as these factors are linked to fetal growth. We used analysis of variance for the adjusted analyses and to compare anthropometric measures such as head and abdominal circumference, birth length, and ponderal index ((birth weight $(\mathrm{g}) /$ birth length $\left.\left.(\mathrm{cm})^{3}\right) \times 100\right)$ between the groups. The risk of preterm birth, being small for gestational age, and an Apgar score of less than 7 at five minutes was assessed by logistic regression analyses. Small for gestational age was defined as a birth weight more than two standard deviations below the mean for gestational age on the reference curve as suggested by Marsal et al. ${ }^{25}$ Preterm birth was defined as delivery before 37 completed weeks of gestation. In secondary analyses we stratified the main results on smoking status at baseline because an interaction between smoking and coffee consumption has been reported. ${ }^{7}$

To determine if women who received decaffeinated coffee increased their consumption of other caffeinated beverages, we calculated the mean intake of caffeine from study coffee, other caffeinated coffee, tea, cola, and drinking chocolate for women in both arms of the study on the basis of information from the interviews.

All reported $\mathrm{P}$ values are two sided, and we defined statistical significance at the 5\% level. We used Stata version $80 \mathrm{SE}$ for all analyses.

If the standard deviation of birth weight was set to $500 \mathrm{~g}$ we calculated that a sample size of 800 women would give $80 \%$ power to detect a difference in birth weight of at least $100 \mathrm{~g}$ at a $5 \%$ two sided significance level.

\section{RESULTS}

Overall 1207 pregnant women were randomised. After exclusions, 568 women were randomised to caffeinated instant coffee and 629 to decaffeinated instant coffee (figure). The groups showed only minor differences in baseline characteristics (table 1).

A total of 1153 women with a liveborn singleton were included in the analysis of birth weight and length of gestation. Of these, $8.6 \%(54 / 629)$ randomised to the decaffeinated group and $4.9 \%$ (28/568) randomised to the caffeinated group dropped out of the study before giving birth. The outcomes for these women were included in the main analysis.

\section{Primary analyses}

Women randomised to caffeinated coffee had a higher mean caffeine intake during the study period. Based on information from the interviews the mean difference in caffeine intake between the groups was $182 \mathrm{mg}$ a day. Table 2 shows the caffeine intake from other beverages.

The mean birth weight for babies born to women in the caffeinated group was $3539 \mathrm{~g}$ (SD $604 \mathrm{~g}$ ) compared with $3519 \mathrm{~g}$ (SD $607 \mathrm{~g}$ ) for babies born to women in the decaffeinated group (table 3). Using the Wilcoxon rank 
sum test no significant difference was found in gestational age between the groups (table $3 ; \mathrm{P}=0.48$ ).

After adjustment for determinants of birth weight at baseline the mean difference in birth weight between babies of women randomised to decaffeinated minus

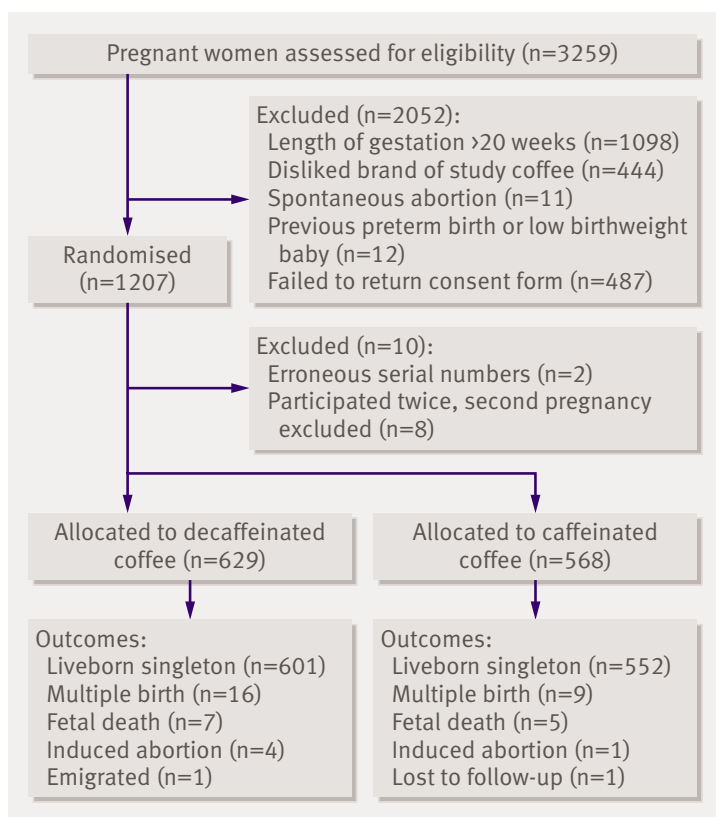

Flow of participants through trial

Table 1| Baseline characteristics of pregnant women randomised to decaffeinated or caffeinated coffee. Values are numbers (percentages) unless stated otherwise

\begin{tabular}{|c|c|c|}
\hline Characteristics & $\begin{array}{l}\text { Decaffeinated } \\
\text { coffee group } \\
(n=629)\end{array}$ & $\begin{array}{l}\text { Caffeinated } \\
\text { coffee group } \\
\quad(n=568)\end{array}$ \\
\hline Mean (SD) age (years) & $30.5(4.3)$ & $30.7(4.3)$ \\
\hline $\begin{array}{l}\text { Mean }(\mathrm{SD}) \text { prepregnancy } \\
\text { weight }(\mathrm{kg})\end{array}$ & $67.8(13.3)$ & $66.8(12.4)$ \\
\hline Mean (SD) height (cm) & $169.0(6.1)$ & $168.6(6.2)$ \\
\hline Mean (SD) gestation (days) & $122.9(14.4)$ & $122.4(14.9)$ \\
\hline \multicolumn{3}{|l|}{ Coffee intake (cups/day): } \\
\hline 3 & $70(11.1)$ & $69(12.2)$ \\
\hline $3-7$ & $262(41.7)$ & $260(45.8)$ \\
\hline$\geq 8$ & $297(47.2)$ & $239(42.1)$ \\
\hline
\end{tabular}

Tobacco consumption

(cigarettes/day):

\begin{tabular}{lcc}
\hline None & $387(61.5)$ & $353(62.2)$ \\
\hline $1-10$ & $155(24.6)$ & $139(24.5)$ \\
\hline$>10$ & $84(13.4)$ & $75(13.2)$ \\
\hline Missing data & $3(0.5)$ & $1(0.2)$ \\
\hline Parity: & & \\
\hline Nulliparous women & $208(33.1)$ & $166(29.2)$ \\
\hline Multiparous women & $413(65.7)$ & $397(69.9)$ \\
\hline Missing data & $8(1.3)$ & $5(0.9)$ \\
\hline Educational level: & $4(0.6)$ & $5(0.9)$ \\
\hline \$9 years & $61(9.7)$ & $48(8.5)$ \\
\hline 9 years & $170(27.0)$ & $160(28.2)$ \\
\hline 10 years & $225(35.8)$ & $224(39.4)$ \\
\hline High school & $169(26.9)$ & $131(23.0)$ \\
\hline Missing data & & \\
\hline
\end{tabular}

caffeinated coffee was $16 \mathrm{~g}$ (95\% confidence interval -40 to $73 ; \mathrm{P}=0.57)$.

\section{Secondary analyses}

The groups were similar for head and abdominal circumference, ponderal index, and placenta weight (table 3).

The difference in mean birth weight and length of gestation between the groups was not modified by coffee consumption at study entry or by compliance with the protocol (table 4). Women who smoked more than 10 cigarettes a day at study entry, however, had babies with a lower mean birth weight of $263 \mathrm{~g}$ (97 to 430; $\mathrm{P}=0.002)$ if they were randomised to caffeinated coffee compared with babies born to women who were randomised to decaffeinated coffee (table 4, test for interaction $\mathrm{P}<0.001)$. On average these women smoked 15 cigarettes a day in the decaffeinated group (interquartile range 13-15) and 16 a day in the caffeinated group (interquartile range 15-20). For women smoking more than 10 cigarettes a day the mean difference in caffeine intake between the groups was $242 \mathrm{mg} /$ day. For non-smokers the mean difference in caffeine intake between the groups was $154 \mathrm{mg} /$ day. When length of gestation was the dependent variable no statistically significant interaction was found between smoking at study entry and randomisation group (test for interaction $\mathrm{P}=0.25$ ).

In the caffeinated and decaffeinated groups, respectively, $4.2 \%(23 / 552)$ and $5.2 \%(31 / 601)$ of infants were born preterm, $4.5 \%(25 / 552)$ and $4.7 \%(28 / 598)$ were small for gestational age, and $0.8 \%(4 / 527)$ and $1.0 \%$ (6/578) had an Apgar score of less than 7 after five minutes. None of these differences was statistically significant.

\section{Compliance}

At about 35 weeks' gestation 53\% (295/552) of women in the caffeinated group and $45 \%(271 / 601)$ in the decaffeinated group drank less than one cup of other

Table 2 | Caffeine intake from various beverages in pregnant women. ${ }^{\star}$ Values are median (interquartile range) caffeine intake (mg/day)

\begin{tabular}{lcc} 
Beverages $\dagger$ & $\begin{array}{c}\text { Decaffeinated coffee } \\
\text { group }\end{array}$ & $\begin{array}{c}\text { Caffeinated coffee } \\
\text { group }\end{array}$ \\
Study coffee & $0(0-0)$ & $195(108-260)$ \\
\hline Other coffee & $67(33-175)$ & $50(33-150)$ \\
\hline Tea & $0(0-50)$ & $0(0-50)$ \\
\hline Cocoa & $0.2(0-1.1)$ & $0.1(0-0.7)$ \\
\hline Cola & $2.9(0-8.6)$ & $3.8(0-8.6)$ \\
\hline Total caffeine & $117(56-228)$ & $317(229-461)$
\end{tabular}

intake

*Based on information from interviews with women of liveborn singletons.

†Amount of caffeine varies with type and amount of coffee used, brewing methods, and cup size. Average estimates of caffeine per cup were: caffeinated study coffee $65 \mathrm{mg}$ (according to manufacturer),

decaffeinated study coffee $0 \mathrm{mg}$; other coffee $100 \mathrm{mg}$; tea $50 \mathrm{mg}$; drinking chocolate and cola per glass $(2 \mathrm{dl}) 5 \mathrm{mg}$ and $20 \mathrm{mg} \cdot{ }^{26}$ Data were not available on size of cups but were available on whether women used regular sized cups or mugs; a mug of coffee was classed as two cups. 


\begin{tabular}{|c|c|c|c|c|c|c|c|}
\hline Variable & $\begin{array}{c}\text { No of } \\
\text { ba- } \\
\text { bies }\end{array}$ & $\begin{array}{l}\text { Decaffeina- } \\
\text { ted coffee } \\
\text { group }\end{array}$ & $\begin{array}{l}\text { Caffeinated } \\
\text { coffee group }\end{array}$ & $\begin{array}{c}\text { Crude } \\
\text { difference }\end{array}$ & $\begin{array}{l}\text { Adjusted difference* } \\
\qquad(95 \% \mathrm{Cl})\end{array}$ & $\begin{array}{l}\text { No of } \\
\text { babies }\end{array}$ & $\begin{array}{c}\text { Adjusted difference } † \\
(95 \% \mathrm{Cl})\end{array}$ \\
\hline Mean birth weight (g) & 1150 & 3519 & 3539 & -19.4 & $4.6(-53.5$ to 62.7$)$ & 1112 & $16.3(-40.0$ to 72.6$)$ \\
\hline $\begin{array}{l}\text { Mean length of gestation } \\
\text { (days) }\end{array}$ & 1153 & 279.3 & 280.2 & -0.92 & $-0.92(-2.45$ to 0.61$)$ & 1115 & $-1.31(-2.87$ to 0.25$)$ \\
\hline Mean birth length $(\mathrm{cm})$ & 1146 & 51.9 & 52.0 & -0.14 & $-0.05(-0.30$ to 0.21$)$ & 1108 & $-0.03(-0.29$ to 0.22$)$ \\
\hline Mean ponderal index & 1145 & 2.5 & 2.5 & 0.01 & $0.01(-0.02$ to 0.04$)$ & 1107 & $0.02(-0.01$ to 0.05$)$ \\
\hline $\begin{array}{l}\text { Mean head circumference } \\
(\mathrm{cm})\end{array}$ & 1006 & 35.1 & 35.1 & 0.03 & $0.07(-0.14$ to 0.27$)$ & 974 & $0.11(-0.10$ to 0.32$)$ \\
\hline $\begin{array}{l}\text { Mean abdominal } \\
\text { circumference }(\mathrm{cm})\end{array}$ & 979 & 33.4 & 33.4 & -0.03 & $-0.001(-0.27$ to 0.27$)$ & 949 & $0.07(-0.19$ to 0.33$)$ \\
\hline Mean placenta weight (g) & 984 & 659 & 673 & -14.7 & $-11.3(-31.0$ to 8.4$)$ & 954 & $-10.6(-30.5$ to 9.3$)$ \\
\hline
\end{tabular}

caffeinated coffee a day; $24 \%(132 / 552)$ and 24\% (147/ $601)$ drank one to three cups of other caffeinated coffee a day, whereas $9 \%(50 / 552)$ and $8 \%(51 / 601)$ drank more than three cups of other caffeinated coffee a day. Information on consumption of other caffeinated coffee at 35 weeks' gestation was missing for $18 \%$ (207/ 1153 ) of the women (72 gave birth before the third interview and 79 had withdrawn their consent). Data from diaries were available on daily caffeine intake from study coffee, other coffee, tea, cocoa, and cola, but only $51 \%$ (293 in each arm) of women returned the diaries (data available on request).

\section{Blinding}

In the caffeinated group 35\% (191/552) of women guessed the type of coffee they received compared with 49\% (296/601) in the decaffeinated group; 20\% $(123 / 601)$ in the decaffeinated group and 22\% (121/ $552)$ in the caffeinated group could not guess. This dif ference in guessing was statistically significant. Information was missing for $10 \%(110 / 1153)$ of women; 82 had withdrawn their consent before the final interview, and 28 were unreachable.

Table 4 | Differences in birth weight and length of gestation between mothers, of liveborn singletons, randomised to receive decaffeinated or caffeinated coffee, stratified on coffee consumption at baseline, compliance to study protocol, and smoking at baseline

\begin{tabular}{|c|c|c|c|c|c|c|}
\hline \multirow[t]{2}{*}{ Variable } & \multicolumn{3}{|c|}{ Birth weight } & \multicolumn{3}{|c|}{ Length of gestation } \\
\hline & $\begin{array}{c}\text { No of } \\
\text { women* }\end{array}$ & Mean difference $(95 \% \mathrm{Cl})$ & $P$ value $\neq$ & $\begin{array}{c}\text { No of } \\
\text { women* }\end{array}$ & $\begin{array}{c}\text { Mean difference } \$(95 \% \\
\mathrm{Cl})\end{array}$ & P valuef \\
\hline \multicolumn{7}{|c|}{$\begin{array}{l}\text { Coffee consumption (cups/ } \\
\text { day) at baseline: }\end{array}$} \\
\hline$\ll 3$ & 131 & $-31(-202$ to 240$)$ & \multirow[t]{4}{*}{0.40} & 131 & $-2.50(-7.4$ to 2.3$)$ & \multirow[t]{4}{*}{0.58} \\
\hline $4-7$ & 480 & 7 (-78 to 92$)$ & & 482 & $-0.27(-2.6$ to 2.0$)$ & \\
\hline$>7$ & 497 & 57 (-28 to 142$)$ & & 498 & $-2.06(-4.5$ to 0.3$)$ & \\
\hline Missing data & 4 & & & 4 & & \\
\hline
\end{tabular}

Consumption (cups/day) of other caffeinated coffeeף:

\begin{tabular}{|c|c|c|c|c|c|c|}
\hline 0 & 283 & $-9(-125$ to 107$)$ & \multirow[t]{6}{*}{0.24} & 283 & 0.38 (-2.0 to 2.8$)$ & \multirow[t]{6}{*}{0.35} \\
\hline$\ll 1$ & 266 & $-39(-150$ to 72$)$ & & 267 & $-1.45(-0.8$ to 3.7$)$ & \\
\hline $1-3$ & 271 & 115 (3 to 226 ) & & 271 & $-1.65(-4.3$ to 1.0$)$ & \\
\hline $4-7$ & 76 & $-120(-354$ to 113$)$ & & 76 & $-0.41(-5.1$ to 4.3$)$ & \\
\hline$\geq 8$ & 21 & $92(-475$ to 659$)$ & & 21 & $-4.39(-18.1$ to 9.4$)$ & \\
\hline Missing data & 195 & 152 (9 to 295) & & 197 & $-2.40(-8.5$ to 3.7$)$ & \\
\hline
\end{tabular}

Smoking (cigarettes/day) at baseline:

\begin{tabular}{llllll}
\hline Non-smoker & 692 & $-48(-118$ to 23$)$ & \multirow{2}{*}{0.001} & 694 & $-0.44(-2.5$ to 1.6$)$ \\
\cline { 1 - 2 } $1-10$ & 272 & $36(-78$ to 149$)$ & & 272 & $-1.80(-4.9$ to 1.3$)$ \\
\cline { 1 - 3 }$>10$ & 148 & $263(97$ to 430$)$ & & 149 & $-4.19(-8.4$ to 0.01$)$ \\
\hline
\end{tabular}

Differences are for decaffeinated minus caffeinated groups.

*Number with information on all covariates and outcome measure.

†Adjusted for parity, smoking, prepregnancy body mass index, and length of gestation.

$\ddagger$ Test for interaction.

§Adjusted for parity, smoking, and prepregnancy body mass index.

ๆConsumption at time of third interview (median 35 gestational weeks). 


\section{WHAT IS ALREADY KNOWN ON THIS TOPIC}

Caffeine intake in pregnancy has been linked to adverse outcome, but evidence from nonexperimental studies on impaired fetal growth remains equivocal

Evidence from randomised controlled trials is lacking

\section{WHAT THIS STUDY ADDS}

A moderate decrease in caffeine intake in the second half of pregnancy had no overall effect on birth weight or length of pregnancy

\section{DISCUSSION}

Providing decaffeinated coffee to women who drank three cups of coffee or more a day in early pregnancy had no effect on birth weight or length of gestation.

We found only small differences in potential confounders at baseline between pregnant women allocated to instant caffeinated coffee and those allocated to instant decaffeinated coffee, and we adjusted for these in analyses.

To ensure good compliance we did not impose a strict protocol on the use of caffeinated beverages during the trial. Still, we obtained a difference in caffeine intake of a magnitude that has previously been reported to have an effect on birth weight. ${ }^{8}$ The difference in caffeine intake we found (182 $\mathrm{mg}$ a day) corresponds to almost three cups of instant coffee a day. We cannot, however, rule out that larger reductions in caffeine may increase birth weight.

Caffeine intake is associated with smoking and alcohol intake, which may influence birth weight. It is possible that a modification of caffeine intake could also influence other lifestyle factors. However, we found no difference between the groups in smoking or alcohol consumption (data not shown).

Women in the decaffeinated group guessed their type of coffee more often than women in the caffeinated group. Women recruited to the study consumed at least three cups of coffee a day, and it is likely that some in the decaffeinated arm had withdrawal symptoms such as headaches. ${ }^{27}$

Slightly more women were randomised to decaffeinated coffee than to caffeinated coffee because of differences between the groups in requesting additional study coffee. When women requested more coffee the first box from the remaining stack of coffee that matched the first supply was chosen. Since women receiving caffeinated coffee requested additional coffee more often we randomised more women to receive decaffeinated coffee. This modification in randomisation probabilities has an effect only on power and not on internal validity of the study.

\section{Comparison with other studies}

Our finding of a possible caffeine effect in smokers may be due to chance, but it has some biological plausibility. Smokers metabolise caffeine faster than non-smokers because smoking induces the CYP1A2 pathway for caffeine metabolism. A previous study found that the caffeine metabolite paraxanthine was associated with fetal growth in smokers, whereas serum caffeine was not. ${ }^{28} \mathrm{~A}$ recent study suggested that CYP1A2 activity, and not the absolute levels of metabolites of caffeine, influences fetal growth. ${ }^{29}$

\section{Unanswered questions and future research}

Our trial was carried out in the second half of pregnancy when the net increase in fetal weight is highest. If caffeine has an effect on birth weight by mechanisms that only operate early in pregnancy we would not detect it. Furthermore, we cannot rule out that substances other than caffeine in coffee may influence birth weight. Our results emphasise that care should be taken when extrapolating results to smokers.

We thank the women who participated in the study, I Snderskov for her support, and M Vaeth for statistical advice.

Contributors: $\mathrm{BHB}, \mathrm{CO}, \mathrm{TBH}$, and $\mathrm{JO}$ designed and initiated the trial. $\mathrm{BHB}, \mathrm{CO}$, and $\mathrm{TBH}$ coordinated the trial, and $\mathrm{BHB}$ analysed the data. All authors met regularly and contributed to trial management; all participated in the interpretation of results and in the writing of the paper. BHB is the guarantor. Funding: The project is supported by a grant from the Health Insurance Foundation (No 1105-93 and 11099-96). The Danish National Research Foundation established the Danish Epidemiology Science Centre that initiated and created the Danish national birth cohort. The birth cohort is furthermore a result of a major grant from this foundation. Additional support for the birth cohort was obtained from the Pharmacy Foundation, the Egmont Foundation, the March of Dimes Birth Defects Foundation, and the Augustinus Foundation. Nestlé was not involved in the design, analyses, or writing of this paper. Competing interests: None declared.

Ethical approval: This study was approved by regional science ethics committees in Denmark and the Danish Data Protection Agency.

1 Knight CA, Knight I, Mitchell DC, Zepp JE. Beverage caffeine intake in US consumers and subpopulations of interest: estimates from the Share of Intake Panel survey. Food Chem Toxicol 2004;42(12):192330 .

2 Aldridge A, Bailey J, Neims AH. The disposition of caffeine during and after pregnancy. Semin Perinatol 1981;5:310-4.

3 Aldridge A, Aranda JV, Neims AH. Caffeine metabolism in the newborn. Clin Pharmacol Ther 1979:25:447-53.

4 Kirkinen P, Jouppila P, Koivula A, Vuori J, Puukka M. The effect of caffeine on placental and fetal blood flow in human pregnancy. $\mathrm{Am}$ J Obstet Gynecol 1983;147(8):939-42.

5 Weathersbee PS, Lodge JR. Caffeine: its direct and indirect influence on reproduction. J Reprod Med 1977;19:55-63.

6 Martin TR, Bracken MB. The association between low birth weight and caffeine consumption during pregnancy. Am J Epidemiol 1987;126(5):813-21.

7 Beaulac Baillargeon L, Desrosiers C. Caffeine-cigarette interaction on fetal growth. Am J Obstet Gynecol 1987;157(5):1236-40.

8 Vlajinac HD, Petrovic RR, Marinkovic JM, Sipetic SB, Adanja BJ. Effect of caffeine intake during pregnancy on birth weight. Am J Epidemiol 1997;145:335-8.

9 Clausson B, Granath F, Ekbom A, Lundgren S, Nordmark A, Signorello LB, et al. Effect of caffeine exposure during pregnancy on birth weight and gestational age. Am J Epidemiol 2002;155:429-36.

10 Shu XO, Hatch MC, Mills J, Clemens J, Susser M. Maternal smoking, alcohol drinking, caffeine consumption, and fetal growth: results from a prospective study. Epidemiology 1995;6:115-20.

11 Fortier I, Marcoux S, Beaulac Baillargeon L. Relation of caffeine intake during pregnancy to intrauterine growth retardation and preterm birth. Am J Epidemiol 1993;137:931-40.

12 Olsen J, Overvad K, Frische G. Coffee consumption, birthweight, and reproductive failures. Epidemiology 1991:2:370-4.

13 Fenster L, Eskenazi B, Windham GC, Swan SH. Caffeine consumption during pregnancy and fetal growth. Am J Public Health 1991;81:458-61.

14 Vik T, Bakketeig LS, Trygg KU, Lund-Larsen K, Jacobsen G. High caffeine consumption in the third trimester of pregnancy: genderspecific effects on fetal growth. Paediatr Perinat Epidemiol 2003;17:324-31.

15 Linn S, Schoenbaum SC, Monson RR, Rosner B, Stubblefield PG, Ryan KJ. No association between coffee consumption and adverse outcomes of pregnancy. N Engl J Med 1982;306:141-5.

16 Eskenazi B, Stapleton AL, Kharrazi M, Chee WY. Associations between maternal decaffeinated and caffeinated coffee 
consumption and fetal growth and gestational duration. Epidemiology 1999;10:242-9.

17 Grosso LM, Rosenberg KD, Belanger K, Saftlas AF, Leaderer AB, Bracken MB. Maternal caffeine intake and intrauterine growth retardation. Epidemiology 2001;11:447-55.

18 Bracken MB, Triche EW, Belanger K, Hellenbrand K, Leaderer BP. Association of maternal caffeine consumption with decrements in fetal growth. Am J Epidemiol 2003;157:456-66.

19 Nawrot P, Jordan S, Eastwood J, Rotstein J, Hugenholtz A, Feeley M. Effects of caffeine on human health. Food Addit Contam 2003;20:1-30

20 Bech BH, Nohr EA, Vaeth M, Henriksen TB, Olsen J. Coffee and fetal death: a cohort study with prospective data. Am J Epidemiol 2005;162:983-90.

21 Cnattingius S, Signorello LB, Anneren G, Clausson B, Ekbom A, Ljunger $E$, et al. Caffeine intake and the risk of first-trimester spontaneous abortion. N Engl/ Med 2000;343:1839-45.

22 Mills JL, Holmes LB, Aarons JH, Simpson JL, Brown ZA, Jovanovic-Peterson LG, et al. Moderate caffeine use and the risk of spontaneous abortion and intrauterine growth retardation. JAMA 1993;269:593-7.
23 Fenster L, Hubbard AE, Swan SH, Windham GC, Waller K, Hiatt RA, et al. Caffeinated beverages, decaffeinated coffee, and spontaneous abortion. Epidemiology 1997;8:515-23.

24 Olsen J, Melbye M, Olsen SF, Sorensen TI, Aaby P, Andersen AM, et al. The Danish National Birth Cohort-its background, structure and aim. Scand J Public Health 2001;29:300-7.

25 Marsal K, Persson PH, Larsen T, Lilja H, Selbing A, Sultan B. Intrauterine growth curves based on ultrasonically estimated foetal weights. Acta Paediatrica 1996;85:843-8.

26 Barone JJ, Roberts HR. Caffeine consumption. Food Chem Toxicol 1996;34:119-29.

27 Juliano LM, Griffiths RR. A critical review of caffeine withdrawal: empirical validation of symptoms and signs, incidence, severity, and associated features. Psychopharmacology (Berl) 2004;176:1-29.

28 Klebanoff MA, Levine RJ, Clemens JD, Wilkins DG. Maternal serum caffeine metabolites and small-for-gestational age birth. Am J Epidemiol 2002;155:32-7.

29 Grosso LM, Triche EW, Belanger K, Benowitz NL, Holford TR, Bracken MB. Caffeine metabolites in umbilical cord blood, cytochrome P-450 1A2 activity, and intrauterine growth restriction. Am J Epidemiol 2006;163(11):1035-41.

Accepted: 28 November 2006 